\title{
Non-parametric and parametric methods using satellite images for estimating growing stock volume in alpine and Mediterranean forest ecosystems
}

\author{
Gherardo Chirici $^{\mathrm{a}, *}$, Anna Barbati ${ }^{\mathrm{b}}$, Piermaria Corona ${ }^{\mathrm{b}}$, Marco Marchetti ${ }^{\mathrm{a}}$, Davide Travaglini ${ }^{\mathrm{c}}$, \\ Fabio Maselli ${ }^{\mathrm{d}}$, Roberta Bertini ${ }^{\mathrm{c}}$ \\ ${ }^{\text {a }}$ Dipartimento di Scienze e Tecnologie per l'Ambiente e il Territorio, Università del Molise, Italy \\ ${ }^{\mathrm{b}}$ Dipartimento di Scienze dell'Ambiente Forestale e delle sue Risorse, Università della Tuscia, Italy \\ ${ }^{\mathrm{c}}$ Dipartimento di Scienze e Tecnologie Ambientali Forestali, Università di Firenze, Italy \\ ${ }^{\mathrm{d}}$ IBIMET, Consiglio Nazionale delle Ricerche, Firenze, Italy
}

Received 26 February 2007; received in revised form 29 December 2007; accepted 1 January 2008

\begin{abstract}
This paper describes applications of non-parametric and parametric methods for estimating forest growing stock volume using Landsat images on the basis of data measured in the field, integrated with ancillary information. Several $k$-Nearest Neighbors $(k-\mathrm{NN})$ algorithm configurations were tested in two study areas in Italy belonging to Mediterranean and Alpine ecosystems. Field data were acquired by the regional forest inventory and forest management plans, and satellite images are from Landsat $5 \mathrm{TM}$ and Landsat $7 \mathrm{ETM}+$. The paper describes the data used, the methodologies adopted and the results achieved in terms of pixel level accuracy of forest growing stock volume estimates. The results show that several factors affect estimation accuracy when using the $k$-NN method. For the two test areas a total of 3500 different configurations of the $k$-NN algorithm were systematically tested by changing the number and type of spectral and ancillary input variables, type of multidimensional distance measures, number of nearest neighbors and methods for spectral feature extraction using the leave-one-out (LOO) procedure. The best $k$-NN configurations were then used for pixel level estimation; the accuracy was estimated with a bootstrapping procedure; and the results were compared to estimates obtained using parametric regression methods implemented on the same data set.

The best $k$-NN growing stock volume pixel level estimates in the Alpine area have a Root Mean Square Error (RMSE) ranging between 74 and $96 \mathrm{~m}^{3} \mathrm{ha}^{-1}$ (respectively, 22\% and 28\% of the mean measured value) and between 106 and $135 \mathrm{~m}^{3}$ ha $^{-1}$ (respectively, $44 \%$ and $63 \%$ of the mean measured value) in the Mediterranean area. On the whole, the results cast a promising light on the use of non-parametric techniques for forest attribute estimation and mapping with accuracy high enough to support forest planning activities in such complex landscapes. The results of the LOO analyses also highlight the importance of a local empirical optimization phase of the $k$-NN procedure before defining the best algorithm configuration. In the tests performed the pixel level accuracy increased, depending on the $k$-NN configuration, as much as $100 \%$.
\end{abstract}

(C) 2008 Elsevier Inc. All rights reserved.

Keywords: $k$-NN; Algorithm configuration; Non-parametric estimation methods; Forest inventory; Forest management planning, Landsat multispectral data

\section{Introduction}

Sustainable forest management (SFM) requires a large amount of information describing and quantifying forest variables. The need for such information has become more pressing in the last decade because of reporting requirements established by numerous international processes: for example, both the Ministerial

\footnotetext{
* Corresponding Author. Dipartimento di Scienze e Tecnologie per l'Ambiente e il Territorio - Università del Molise, Contrada Fonte Lappone, 86090 Pesche, Isernia, Italy. Tel.: +390874404113 ; fax: +390874404123

E-mail address: gherardo.chirici@unimol.it (G. Chirici).
}

Conference on the Protection of Forests in Europe (2002) and the Montreal Process (2006) require periodic country reports for multiple SFM indicators.

Data for most forest variables used to derive SFM indicators are traditionally acquired over large areas by forest inventories or, at the local level, by forest management plans. At both scales, information comes from expensive field surveys.

Data obtained from remotely sensed images, augmented by other ancillary data (Tomppo \& Halme, 2004), have been used as proxies for qualitative and quantitative forest variables measured or assessed in the field (Franklin, 2001; Kilpeläinen \& Tokola, 1998; McRoberts \& Tomppo, in press; McRoberts et al., 